\title{
Chemical Profile of Cocaine Seizures and Its Adulterants in Morocco
}

\author{
Hamid STAMBOULI* and Aziz EL BOURI \\ Department of Forensic science, Royal Gendarmerie Forensic Science Institute, Morocco \\ *Corresponding author: Hamid STAMBOULI, Department of Forensic science, Royal Gendarmerie Forensic Science Institute, Morocco

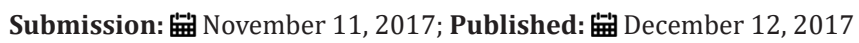

\begin{abstract}
This paper concerns the chemical profile of 154 samples collected from cocaine seizures made by units of the Moroccan royal gendarmerie during the period $2007-2016$. This retrospective study shows that $84 \%$ of seized products are adulterated with a purity variable from $17 \%$ to $90 \%$. The main drug-type additives detected remain levamisole and phenacetin, in accordance with international data. However, some differences were found in comparison with these same data, principally for minor constituents, caffeine, lidocaine, paracetamol and hydroxyzine. This differentiation could be beneficial for chemical profiling of cocaine seizures.
\end{abstract}

Keywords: Forensic investigation; Cocaine; Adulterants; Purity; Levamisole; Phenacetin

Abbreviations: ICGR: Institut de Criminalistique de la Gendarmerie Royale; UNODC: United Nations Office on Drugs and Crime; GC-FID: Gas Chromatography Equipped with Flame Ionization Detector; GC-MS: Gas Chromatography Coupled to Mass Spectrometry)

\section{Introduction}

The use of cocaine, according to UNODC, remains relatively concentrated in the Americas, Europe and Oceania. Production is almost exclusively concentrated in South America, where cocaine cultivation has increased by $30 \%$ between 2013 and 2015. At the same time, the worldwide production of cocaine hydrochloride in 2015 has reached 1125 tons, showing an increase of 25\% comparatively to 2013. For cocaine seizures, they have increased by $36 \%$ from 634tons in 2011 to 864 tons in 2015 [1]. For Morocco, its geographical location and airport infrastructure have led traffickers to use the country as a transit zone to Europe from Latin America. It is smuggled via sub-Saharan Africa and several seizures are regularly made on African people in transit to Europe at the Mohammed V international airport of Casablanca. In 2016, investigations against the drug cartel conducted to the seizure of $250 \mathrm{~kg}$ in Oujda region in the east of the country and $1230 \mathrm{~kg}$ in a boat intercepted in Moroccan territorial seas. Year 2017 was marked by a record seizure of 2.5 tons of cocaine in the Rabat region. In parallel with this transit circuit, there is also a marketing network for this drug for local consumption.

Seizures of cocaine contain mainly the natural alkaloids of the coca plant (Erythroxylon coca), including the active ingredient cocaine, together with cis and trans-cinnamoylcocaine, methyl ecgonine, benzoylecgonine, tropacocaine, etc. This chemical composition with purity between $80-90 \%$ (cocaine hydrochloride) is often intended for international traffic. For local traffic, an adulteration is made by adding diluents and where the purity of cocaine is reduced to about $30 \%$ [2]. A review of the forensic literature identified 48 additives reported in cocaine analysis: 35 active additives, 9 inert additives and 4 volatile compounds [3]. It is also reported that adulteration practices with harmless substances, such as sugars or caffeine, are similar in Europe, the United States, Canada and Australia [4]. In the United States, the average purity of cocaine between 2003 and 2007 remained relatively stable between $65 \%$ and $70 \%$ [5].

During forensic investigations, the determination of the cocaine purity and the chemical characterization of its cutting products remain potential indicators leading to make comparisons between various seizures and determination of their origin. Retrospective statistical studies of cocaine analysis results are important tools for drawing up the chemical profiles of cocaine seizures to help the authorities combating against drug trafficking. The present study aims to establish the chemical profile of cocaine seizures carried out in Morocco. It concerns a retrospective study of the cocaine purity and its cutting products in representative samples of cocaine analyzed in the ICGR between 2007 and 2016.

\section{Materials and Methods}

The study of cocaine chemical profile and its adulterants is carried out on 154 samples of powders analyzed at ICGR, from seizures made by units of the Moroccan Royal Gendarmerie during the period 2007-2016 (Table 1). 
Table 1: Distribution of cocaine samples studied (2007-2016).

\begin{tabular}{|c|c|c|c|c|c|c|c|c|c|c|}
\hline Year & 2007 & 2008 & 2009 & 2010 & 2011 & 2012 & 2013 & 2014 & 2015 & 2016 \\
\hline Nb/Samples & 14 & 6 & 12 & 29 & 8 & 20 & 14 & 9 & 22 & 20 \\
\hline
\end{tabular}

The determination of cocaine content in each sample is conducted by the same method recommended by UNODC [2], consisting of an organic extraction followed by GC-FID analysis and quantification by internal calibration. The chemical characterization of the adulterants is carried out on the same organic extract analyzed by GC-MS.

\section{Extraction Procedure}

Ethanol used for extraction is analytical grade and supplied by VWR. The standard substances deuterated cocaine and nonadecane come respectively from LGC and Sigma Aldrich. For extraction, a representative sample of $50 \mathrm{mg}$ of powder is processed with $10 \mathrm{ml}$ of ethanol solution of $0.5 \mathrm{mg} / \mathrm{mL}$ of nonadecane. The extraction is carried out by ultrasonic stirring for 15 minutes and the resulting solution is then dried over magnesium sulfate and filtered. A volume of $500 \mu \mathrm{L}$ of the solution is diluted in $1 \mathrm{~mL}$ of ethanol, homogenized and then $1 \mu \mathrm{L}$ aliquot is analyzed by GC-FID and GC-MS.

\section{Analysis and Calculations}

The cocaine content of the drug samples is evaluated in GC-FID with calibration method by deuterated cocaine standard solutions. The results are expressed in percentages relative to the weight of powder [2]. The identification of cocaine and its adulterants is performed in GC-MS by comparing their mass spectra with the NIST library.

\section{Instrumentation}

GC-FID analysis is performed on Agilent 6890N instrument, equipped with split/splitless injector and flame ionization detector. The separation is carried out on Agilent capillary column HP-5 (5\% methyl-phenylsiloxane, $30 \mathrm{~m} \times 0.2 \mathrm{~mm} \times 0.2 \mu \mathrm{m}$ ) with helium as carrier gas. The following oven temperature program is adopted: isothermal $60^{\circ} \mathrm{C}$ for $2 \mathrm{~min}$, ramp $15^{\circ} \mathrm{C} / \mathrm{min}$ and isotherm $280^{\circ} \mathrm{C}$ for $5 \mathrm{~min}$. The injector is heated at $270^{\circ} \mathrm{C}$ and the FID detector at 280 ${ }^{\circ} \mathrm{C}$. These same conditions are used in GC-MS with Agilent 5975C mass detector (Electronic Impact $70 \mathrm{eV}$ ) and an interface heated at $280{ }^{\circ} \mathrm{C}$.

\section{Results and Discussion}

\section{Purity of cocaine and chemical profile of adulterants}

Among the 154 cocaine samples analyzed, 129 products are adulterated ( $84 \%$ of seizures) and their purity varies between $17 \%$ and $90 \%$ depending on the proportions of additives added. Only 3 cases recorded in 2009, 2015 and 2016 deviate from this interval because of a very high adulteration resulting in very low cocaine contents respectively about $1 \%, 7 \%$ and $10 \%$. The other 25 samples don't contain adulterants and their purity is between $66 \%$ and $95 \%$. The majority of these pure products $(96 \%)$ are in hydrochloride form.

A total of sixteen different adulterants were identified in the cocaine samples analyzed. Six main drug-type additives were regularly detected, corresponding in the order of frequency to levamisole $(63.40 \%)$, phenacetin $(29.10 \%)$, diltiazem $(14.20 \%)$, caffeine $(8.20 \%)$, lidocaine $(5.20 \%)$ and paracetamol $(3.00 \%)$ (Figure 1).

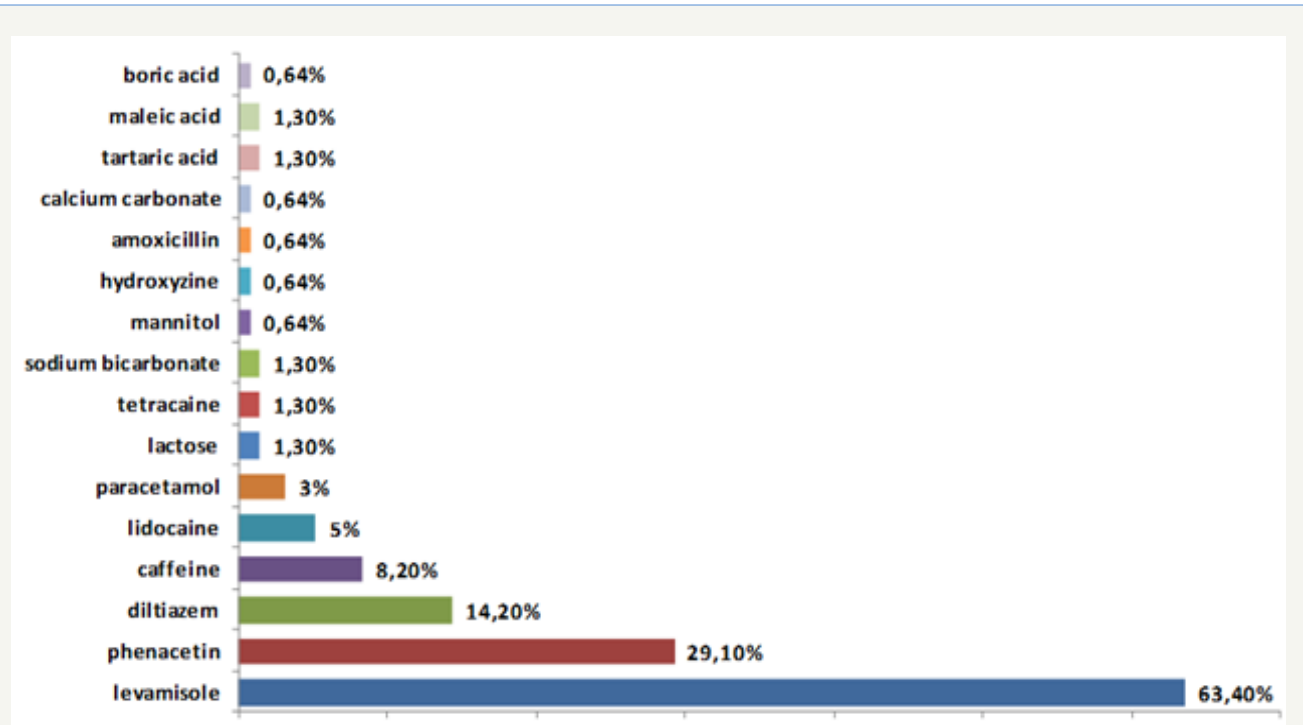

Figure 1: Cutting products frequently found at the Forensic Institute of Royal Gendarmerie between 2007 and 2016 (analysis of 154 powders). 
The ten other cutting products detected less frequently correspond to sugars lactose $(1.30 \%, 2$ cases in 2010$)$ and mannitol (0.64\%, 1 case in 2009), drugs tetracaine (1.30\%, 2 cases in 2009 and 2011), hydroxyzine $(0.64 \%, 1$ case in 2012) and amoxicillin (0.64\%, 1 case in 2012), organic acids such as tartaric acid $(1.30 \%$, 2 cases in 2016) and maleic acid (1.30\%, 2 cases in 2016) and mineral additives sodium bicarbonate $(1.30 \%, 2$ cases in 2010 and $2015)$, calcium carbonate $(0.64 \%, 1$ case in 2010$)$ ) and boric acid (0.64\%, 1 case in 2016).

More than half of the adulterated samples (60\%) contain only one adulterant, $25 \%$ contain two adulterants simultaneously and $13.40 \%$ contain three adulterants. In a particular case in 2009 , five adulterants were counted in the same sample. The combination levamisole/phenacetin has been widely found $(27.70 \%$ of adulterated samples).

\section{Chronological evolution of the adulteration}

It seems that diltiazem, which has been predominant before 2010, was replaced in 2009 by phenacetin and levamisole before disappearing completely in 2011 (Figure 2). The latter adulterant has begun since 2014 to supplement the use of phenacetin and is currently the cut product most found in cocaine seizures.

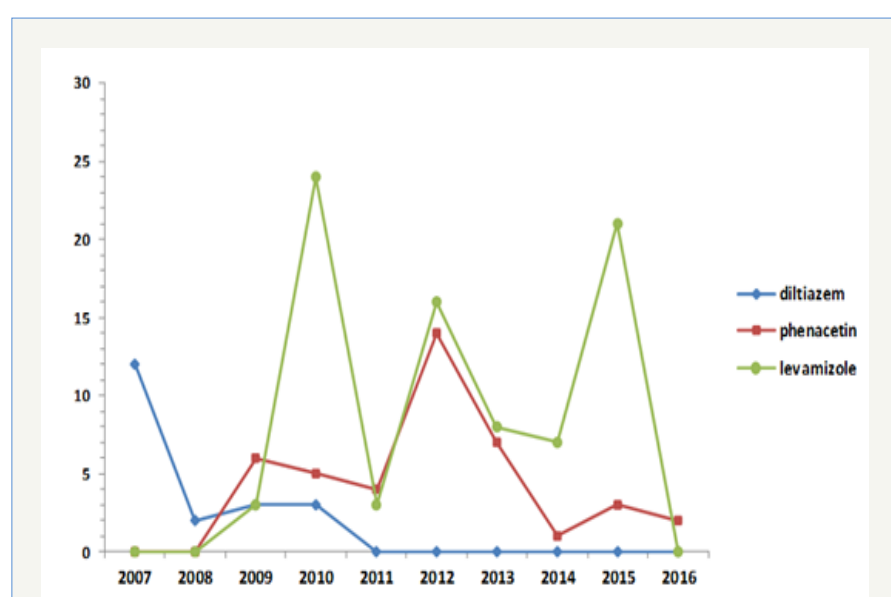

Figure 2: Evolution of the main cutting products frequently found at the Forensic Institute of Royal Gendarmerie between 2007 and 2016 (analysis of 154 powders).

These results confirms the international trend because levamisole, which represents the main adulterant encountered in this study (63\%), appeared in France in 2003 and its presence in cocaine seizures analyzed has increased significantly to $61 \%$ of samples in 2010 [6]. The same situation was also notified in samples from other European countries [7] and the United States, where the presence of this substance in cocaine appeared since 2002, and has increased owing to the fact that $70 \%$ of cocaine seizures analyzed by US authorities in July 2009 contained levamisole [8].

For phenacetin, the second common adulterant according to the results of our study (29\%), this substance was also frequently found in France, in 41\% of the cocaine samples seized in 2010. We can note that the use of this substance as adulterant has begun to decline significantly since 2014 in favor of levamisole.
Finally, diltiazem detected in $14 \%$ of cases, especially in 2007 2008 , seems to have been abandoned by traffickers since its last appearance in cocaine seizures in Morocco dates back to 2010. This result is consistent with literature [6] which specify that this adulterant is no more used $(<5 \%)$, even if it had been mainly used in 2007.

\section{Quantitative aspect and profiling}

The percentages of addition of the two main adulterants, levamisole and phenacetin, remain variable and are respectively in the interval $[<1-33 \%]$ and $[<1-51 \%]$. These results are consistent with the literature [6] which notes a lower concentration of levamisole (average concentration of $9 \%$ in 2010) compared to phenacetin (10-30\%).

Regarding other adulterants detected less frequently according to our study, caffeine (8\%), lidocaine $(5 \%)$ and paracetamol (3\%), their content remains relatively low $(<1 \%)$ but with respective peaks recorded punctually in 2011 (20\%), 2010 (22\%) and 2012 $(32 \%)$. The results are therefore quite distinct from the European data, which indicates that the addition of caffeine has increased since 2003; and in 2010, it was detected in $30 \%$ of cocaine samples seized. Similarly, lidocaine is also present as a cocaine cutting product in about 10 to $15 \%$ of all seizures analyzed by police in France since 2003; and its average concentration varies between $14 \%$ and $20 \%$ since 2008 . For paracetamol, its use seems to be rare in France but for hydroxyzine, it is constantly increasing (present in 20\% of cocaine samples seized in 2010 in France), unlike Moroccan seizures (only 1 case in 2012).

In the end, levamisole and phenacetin remain the two main adulterants detected in cocaine seizures in Morocco, which is in line with international trends, especially in Europe. In addition, the differences in the chemical profiles highlighted in this study compared to European data, particularly for the minor constituents caffeine, lidocaine, paracetamol and hydroxyzine, argue for the existence of several international routes of cocaine trafficking [6].

\section{Conclusion}

The cocaine seized in Morocco mainly corresponds to adulterated powders and its purity varies between $17 \%$ and $90 \%$. The main cut products detected remain levamisole and phenacetin, in accordance with European data. In contrary, difference in chemical profiles was found compared to these same data, with regard to the frequency and content of minor constituents, caffeine, lidocaine, paracetamol and hydroxyzine. This result would mean, assuming that the cutting is not done locally, that cocaine seized in Morocco using African sub-Sahara, Atlantic coast or in transit by air, seems to have slight chemical dissimilarities, compared to that circulating in Europe coming probably from north old continent ports. This differentiation could be helpful for cocaine seizures chemical profiling and approaching their origin.

\section{References}

1. World Drug Report (2017) United Nations Office on Drugs and Crime. 
2. (2012) Recommended methods for the identification and analysis of cocaine in seized materials. United Nations Office on Drugs and Crime, New York, USA

3. Shesser R, Jotte R, Olshaker J (1991) The contribution of impurities to the acute morbidity of illegal drug use. Am J Emerg Med 9(4): 336-342.

4. Cole C, Jones L, McVeigh J, Kicman A, Syed Q et al. (2010) CUT: A Guide to adulterants, bulking agents and other contaminants found in illicit drugs. Public Health Institution, ISBN: 978-1-907441-48-6: 10-25.

5. Fries A, Anthony RW, Cseko A, Gaither CC, Schulman E (2008) The price and purity of illicit drugs: 1981-2007. IDA-P-4332. Institute for Defense
Analyses, Virginia, USA.

6. Lahaie E (2012) Cocaïne, données essentielles. Maud Pousset (Ed), OFDT, Saint-Denis, France: 40-41.

7. Monzon E, Courné MA (2014) Bulletin de l'Agence Nationale de Sécurité du Médicament et des Produits de Santé ANSM. Vigilances-Bulletin ${ }^{\circ}$ 62.

8. (2009) Nationwide public health alert issued concerning lifethreatening risk posed by cocaine laced with veterinary anti-parasite drug. Substance Abuse and Mental Health Services Administration. 